LABOR SUPPLY EFFECTS OF WINNING A LOTTERY

Matteo Picchio, Sigrid Suetens And Jan C. VAn OuRS

QUADERNO DI RICERCA n. 416

ISSN: 2279-9575

January 2016 
Comitato scientifico:

Marco Gallegati

Stefano Staffolani

Alessandro Sterlacchini

Alberto Zazzaro

Collana curata da:

Massimo Tamberi 
JEL Class.: J22, J29

Keywords: Labor supply; income effects; wealth shocks; lottery players

Indirizzo: Matteo Picchio. Department of Economics and Social Sciences, Marche Polytechnic University, Ancona, Italy; CentER, Tilburg University, The Netherlands; IZA, Bonn, Germany. E-mail: m.picchio@univpm.it.

Sigrid Suetens. Department of Economics, CentER, Tilburg University, The Netherlands. E-mail: s. suetens@uvt.nl. Jan C. van Ours. Corresponding author. Department of Economics, CentER, Tilburg University, The Netherlands; Department of Economics, University of Melbourne, Parkville, Australia; CEPR, London; CESifo, Munich; CREAM, London; IZA, Bonn. E-mail: vanours@uvt.nl. 



\title{
Labor Supply Effects of Winning a Lottery*
}

\author{
Matteo Picchio, Sigrid Suetens and Jan C. van Ours
}

\section{Introduction}

Income and wage affect the labor supply of individuals. Unless leisure is an inferior good, a change in wages has ambiguous effects on the preferred hours of work because the income effect and substitution effect work in opposite direction. A large part of the empirical literature on labor supply is focused on how a change in wages affects preferences for hours of work, disentangling the income effect from the substitution effect. However, the estimation of labor supply elasticities faces a number of problems (see Keane, 2011, for a discussion). The main problems are related to measurement errors in wages and non-labor income, endogeneity of wages and non-labor income arising from simultaneity or correlation with tastes for work, and unobservability of wages for non-workers. Labor supply changes due to changes in non-labor income may be informative about the income effect but such changes may be endogenous. Individuals with a strong preference for work and weak preferences for leisure may accumulate more assets and therefore have more non-labor income.

Our study presents an analysis of the effects of non-labor income on labor supply using information about lottery prize winners in the Netherlands. Data from lottery prize winners are informative on how labor supply is affected by an exogenous non-labor income shock. ${ }^{1}$ The psychology literature reports about a number of surveys of lottery winners. These suggest that lottery prizes tend to reduce labor supply for some individuals but not for the majority of prize winners. Kaplan (1987) analyzes a survey of 576 US lottery winners of whom 139 won 1 million dollar or more. Although the majority of the prize winners did not change their work behavior, of the million dollar winners, 1 in 4 stopped working. Not surprisingly, of the winners of less than 50,000 dollars none stop working. This is in line with Arvey et al. (2004) who survey 117 US lottery winners finding that most winners continue working while

* The authors thank the Dutch State Lottery and, in particular, Remco van Gastel and Arjan van 't Veer for their cooperation and for making the lottery data available for analysis, and Cyrille Fijnaut and Eric van Damme for establishing the contacts with the State Lottery. The authors also thank Statistics Netherlands (CBS) for making their data available for analysis through a remote access facility. The authors are grateful to participants in the AIEL conference in Cagliari, Italy (September 2015) for their comments and suggestions.

\footnotetext{
${ }^{1}$ Alternatively, the issue of potential endogeneity of non-labor income may be addressed by focusing on labor supply effects of unanticipated inheritances. See for example Joulfaian and Wilhelm (1994) on earnings, and Goodstein (2008) and Brown et al. (2010) on the probability of retirement. In addition, changes in labor supply have also been linked to booms and busts in stock markets, assuming that at least part of these booms and busts are unforeseen. See for example, Hurd et al. (2009) on retirement.
} 
only some quit their job or start working part-time. Similar conclusions are drawn in a series of studies based on a survey of 420 Swedish lottery winners. Hedenus (2012) concludes that the majority did not make any adjustment to their working life. Of the others some stopped working, took unpaid full-time leave several times, or reduced their working hours for a shorter or longer period. Furaker and Hedenus (2009) find that few prize winners stopped working, some of them took unpaid full-time leave, but for the vast majority this is less than a month. Some prize winners reduced their working hours, but on average less than 10 hours per week. Hedenus (2009) concludes that young winners living alone take periods of unpaid leave while female prize winners without children at home reduce their hours of work.

There are also a number of studies in the economics literature that exploit information about lottery prize winners to study labor supply effects. Imbens et al. (2001) use data from the Megabucks lottery in Massachusetts, played in the 1980s, where major prizes are paid out in yearly installments over twenty years, to estimate labor supply effects. They contacted prize winners and asked them questions concerning labor earnings, and an authorization of the release of their Social Security earnings. They find significant income effects, and report a marginal propensity to consume leisure of about 0.11 , indicating that an increase on non-labor income of $\$ 100,000$ would reduce earnings by $\$ 11,000$. Kuhn et al. (2011) survey winners from the Dutch Postcode Lottery to measure labor market participation and do not find significant effects on earnings. ${ }^{2}$ Jacob and Ludwig (2012) study the effects of a housing voucher lottery on labor supply of low-income families in Chicago in the late 1990s. Given that supply of housing vouchers far exceeded demand, a lottery was installed to randomly allocate the vouchers. Families who received the voucher, experienced an increase in permanent income, but also a reduction in their wages through an increase in their marginal tax rate. The authors compare employment and earnings in families who applied and were not offered a voucher with families who applied and were offered a voucher. They find that the housing vouchers reduce both the employment and earnings, and calibrate an income elasticity of -0.09 . They also report that the housing vouchers reduced the employment rate of women by $6 \%$, whereas there is no effect on employment of men. Most closely related to our study is Cesarini et al. (2015), who study the effect of lottery prizes on individual and household labor supply in a panel data set of Swedish lottery players. They find significant responses at the intensive and extensive margin. To illustrate, they find that winning a lottery prize immediately and permanently reduces earnings for more than 10 years with an estimated lifetime marginal propensity to consume leisure of about 0.10 . They do not find significant differences according to age or gender.

In our paper, we use panel data from winners of lottery prizes in the Dutch State Lottery and match these with data on individual-level labor supply and with household-level administrative data. Studying the Dutch labor market is particularly interesting. Whereas in many countries adjusting weekly working hours is not easy, in the Netherlands it is usually no problem for

\footnotetext{
${ }^{2}$ This result is not surprising given that the size of the prize is either $€ 12,500$ or a BMW-car, so likely not sufficiently high to induce changes in labor market behavior.
} 
workers to adjust their working hours. In the last twenty years, the Dutch government has indeed implemented some policies aimed at removing barriers to part-time work, culminating in 2000 with the possibility for workers to flexibility adjust upward or downward the number of working hours within their current job, unless the request is in conflict with employers' business interest. As a matter of fact, in the Netherlands both among females and males there are many part-time workers. ${ }^{3}$

We track lottery players and winners over a number of years and study their labor supply responses focusing on employment and earnings. Labor market information from lottery prize winners is an ideal source for estimating the effect of income shocks on labor supply. For one, they come from a random draw and are thus as close as one can get to an unforeseen, random shock in permanent income. Moreover, lottery prizes are unearned and potentially substantial in size. ${ }^{4}$ Our main findings are the following. Winning a substantial lottery prize affects the intensive margin of labor supply but not the extensive margin of labor supply. The lottery prize effects last for several years which suggests that the unexpected non-labor income is used for intertemporal smoothing of labor supply. We also find that the labor supply responses materialize predominantly among younger single individuals without children, which is in line with Hedenus (2009).

Our parameter estimates indicate that, overall, a lottery prize of $€ 100,000$ leads to a drop in labor earnings of about $€ 1,100$ after 1 year, of $€ 1,600$ after two years, and of almost $€ 1,800$ after 3 years. In order to compare our findings to estimates in the literature, we calculate the marginal propensity to consume leisure by adding up the reduction in earnings over the first 3 years, which is about $€ 4,500$. The implied marginal propensity to consume leisure would be equal to 0.045 . This is lower than the marginal propensities to consume reported by Imbens et al. (2001) and Cesarini et al. (2015) (0.11 and 0.10, respectively). However, given that we can only calculate the effect over the first 3 years whereas it may persist over a longer period, it rather represents a lower bound.

Our contribution to the labor supply literature is threefold. First, we add to the small literature that exploits lottery data to analyze how exogenous shocks to non-labor income affect earnings and employment. Second, as indicated before, we analyze labor supply behavior in a labor market in which workers can easily adjust their labor supply at the intensive margin. Third, our data allow us to explore the heterogeneity of the labor supply effects and indeed we find that this is important.

Our paper is set up as follows. In Section 2 we describe the different data sets and provide descriptive statistics. In Section 3 we present the econometric results. Section 4 concludes.

\footnotetext{
${ }^{3}$ In the Netherlands, in 2013 the average fraction of part-time workers on total employment (15-64 years) was $26.2 \%$ for men and $77.0 \%$ for women. In the European Union (15 countries), the same statistics were $9.7 \%$ for men and 38.2\% for women (Eurostat, Labour Force Survey, http://ec.europa.eu/eurostat/web/lfs/data/database).

${ }^{4}$ Note that once a person enters a lottery, winning the lottery is a random event, exogenous to labor supply. However, participation in a lottery is not a random event. Individuals with a strong preference for leisure may be more likely to participate in the lottery. We return to this issue below when we discuss our econometric model.
} 


\section{The data}

Our empirical analysis is based on data sets from two sources. The first source of data is the State Lottery in The Netherlands (www.staatsloterij.nl). The State Lottery data set contains information of the State Lottery subscribers in the time window 2005-2008. The second data source is Statistics Netherlands. From Statistics Netherlands we use two data sets also spanning the period from 2005 until 2008: the Municipal Personal Records Database (GBA), containing demographic, family, and residence information of all the people registered in a Dutch municipality and the Social Statistical Database of Jobs (SSB Jobs), containing information on salaried jobs.

In order to guarantee anonymity and confidentiality, the lottery data set and the GBA data set were merged by Statistics Netherlands on the basis of the day of birth and address of individuals. Specifically, Statistics Netherlands was provided with a sample of lottery players with information on their day of birth, address, lottery prizes, and expenditures in lottery tickets by year. Statistics Netherlands matched this sample with the GBA data set, and then gave us permission to work with the linked data set on a terminal located in the Department of Economics of Tilburg University and connected via internet to their servers through a secure connection. In what follows, we describe more in detail the data sets used in this study, and the steps taken to come to the final sample used in the main analysis.

\subsection{The lottery data}

The Dutch State Lottery sells lottery tickets and organizes monthly draws of a number of winning tickets. Additional draws (maximum three) are organized at special occasions throughout the year, for example, at the end of the year ("Eindejaarstrekking") and at Queen's day ("Koninginnedag"). ${ }^{5}$ Each ticket consists of a combination of two letters and six numbers. ${ }^{6}$ Whether an individual wins a prize and the amount of the prize depend on the degree of correspondence between the letters and numbers on the individual's ticket and those on the tickets drawn. The prize amount also depends on the type of ticket: people can choose between "full" tickets and "partial" tickets. A full ticket costs $€ 15$ and pays the full amount if it is a winning ticket. A partial ticket costs $€ 3$ and pays one fifth of the full prize if it is a winning ticket. The full prizes in each draw vary from $€ 5$ to $€ 1$ million. In each draw, the main prize of $€ 1$ million (or one fifth of it) is guaranteed for one of the tickets. Draws are repeated until someone wins the main prize. In each draw, also 10 prizes of $€ 100,000,10$ prizes of $€ 25,000$, and 20 prizes of $€ 10,000$ are allocated to winning tickets. Each draw also has a number of smaller prizes, ranging from $€ 5$ to $€ 1,000$, which are allocated to tickets in which only part of the numbers overlap with the ones on the winning tickets. For example, in each draw a winning "end number" is drawn. Tickets with codes ending with this number pay a $€ 5$ prize. Finally, for an

\footnotetext{
${ }^{5}$ In the period of study, there were 55 draws in total (13 in 2005, 14 in 2006, 2007 and 2008).

${ }^{6}$ Lottery players do not choose the full combination themselves when they buy a ticket. Instead, they can only choose the last one or two numbers. See also footnote 9.
} 
additional amount of money (about 15\% extra), players can also play for the so-called "Jackpot". 7 The Jackpot is an additional large prize of at least $€ 7.5$ million, of which the amount is decided by the State Lottery. The Jackpot is not guaranteed in each draw and, if there is no ticket that wins the Jackpot in a certain draw, the full amount is transferred to the next one. ${ }^{8}$

About half of the individuals who bet in the State Lottery in The Netherlands do so through a subscription. ${ }^{9}$ Each month an amount of money is automatically transferred from their bank account to the State Lottery's bank account. For each subscriber, we have information about the amount of prizes they won in each draw in the period 2005-2008 with the ticket(s) bought through the subscription, and the amount they spent on the subscription in each of these years. ${ }^{10}$ The data set consists of 1,975,665 individuals who subscribed for at least one draw of the State Lottery between 2005 and 2008. In total, 1,913,901 individuals won a strictly positive (but possibly very small) prize. Out of these, we draw a sample of individuals that consists of two subsamples. The first subsample includes all subscribed individuals who won more than $€ 1,000$ in the sample period, which amounts to 7,663 individuals in total. The second subsample consists of a $1 \%$ sample of the remaining subscribers, in total 22,070 individuals.

Our total sample of State Lottery winners, before being matched with the administrative data sets of Statistics Netherlands, thus consisted of 29,733 individuals. For these individuals, we know how much they spent on lottery tickets in each year and how much prize money they win in each year, both through their subscription. ${ }^{11}$

\footnotetext{
${ }^{7}$ Unfortunately, we do not have detailed information about which players pay the extra $15 \%$ to play for the Jackpot.

${ }^{8}$ Table A.1 in Appendix A provides details about the current prize structure. Each year the State Lottery slightly changes the prize structure. In 2005 a main change took place: the Jackpot was introduced and the relative number of large prizes was reduced. Whether or not the Jackpot is paid depends on a separate lottery which consists of a random draw of one ball out of 6 blue balls and 1 orange ball. If the orange ball is drawn, the Jackpot is paid to one of the lottery players who paid the additional amount of money of $15 \%$. If a blue ball is drawn, no Jackpot is paid and the Jackpot rolls over to the next draw and is now $€ 15$ million. If a blue ball is drawn this ball is removed from the next lottery which then consists of 5 blue balls and 1 orange ball. If then again a blue ball is drawn, the Jackpot again rolls over and the draw is from 4 blue balls and 1 orange ball. The draw after one with an orange ball restarts with 6 blue balls and 1 orange ball.

${ }^{9}$ Subscribers only have the option to choose the last number of the combination of two letters and six numbers on a ticket. They have three options: (1) use the same combination in every draw (of which only the last number is chosen by the subscriber), (2) use a randomly drawn combination in every draw, or (3) use the same, self-chosen last number in every draw combined with a randomly drawn combination of other numbers and letters.

${ }^{10}$ To be more precise, the information we have about the amount spent by the players consists of expenditures by draw that the State Lottery has estimated. It consists of the expected (by the State Lottery) yearly amount the player would spend on lottery tickets if he/she would continue his/her subscription for one additional year at the moment of the draw. Because the labor market data are only available at a yearly basis, we calculated the expenditures of the players on a yearly basis simply by taking the average of the estimated (yearly) expenditures across all draws in a year.

${ }^{11}$ We calculated the yearly expenditures by taking the average of the expected yearly expenditures across all draws in each year.
} 


\subsection{The demographic and labor market data}

The data on demographics are in the GBA database and the data on salaried jobs are in the SSB Jobs database. Both databases contain an individual identifier, which allows the data from both sources to be linked. The GBA database includes the date of birth and the address of residence of the individuals, as well as identifiers of other members of the individual's household. The latter information makes it possible to study the impact of lottery prizes at the family level as well, next to the effects at the individual level. The SSB Jobs database contains information at the level of each single job of individuals employed by an employer located in the Netherlands.

In a first step, Statistics Netherlands merged our lottery data set with the GBA database on the basis of the date of birth and the address of residence of the lottery players. Statistics Netherlands was able to match about $62 \%$ of the individuals of our State Lottery data set to the GBA database. $^{12}$

In a second step, we linked the merged data set that resulted from the first step with the SSB Jobs database. ${ }^{13}$ In order to calculate the annual labor earnings we summed up all earnings on a yearly basis across the different jobs held by each employee during the year. After this second step, we are left with a sample of 60,601 lottery prize observations covering 18,390 individuals, for whom we have information about the yearly gross salaries from 2005 until 2008.

In a third step, we restricted the sample to the working-age population, namely to those individuals who are above 17 and below 65 years of age at the time of the lottery win. This left us with 45,328 lottery prize observations covering 13,391 individuals. ${ }^{14}$ In our main analysis, we focus on those individuals who are at work in a salaried job in the year of the prize win. The reason is that we expect a decrease in earnings or employment caused by winning a high lottery prize to occur only for those individuals who have a job in the first place. Our main analysis is based on 35,525 observations, corresponding to 10,871 individuals. In order to check for the robustness of our results, we also report the results from regressions including people who do not have a salaried job in the year of the lottery win. Table 1 gives an overview of the distribution of yearly prizes (a) in the original State Lottery data set, (b) after merging of the lottery, demographic and labor market data, and (c) in the final sample of players who have a

\footnotetext{
${ }^{12}$ This means that $38 \%$ of the players in our sample could not be matched. For $22 \%$ of the players in our sample no birth date is available. The remaining $16 \%$ is lost because of mistakes in the date of birth and postal addresses, for example, because players have moved between the point in time their data was entered in the lottery data set and the (more recent) time their data was adjusted in the GBA database. We have no information to determine which fraction of the loss is due to actual mistakes in the coding or due to players moving.

${ }^{13}$ Roughly all individuals who are in the SSB Jobs database can be linked to the GBA database. Exceptions are individuals who work in the Netherlands and live outside the Netherlands, but this is a negligible fraction of the labor market population, and irrelevant for the sample of State Lottery players.

${ }^{14}$ Also, since we focus on "standard" individuals, we removed observations related to individuals who are not single, nor living in a couple. These observations come, for example, from young individuals who live with their parents, or from individuals who live in a large family, which is very uncommon. In addition, we removed the observations covering winners of the Jackpot lottery prizes larger than $€ 10$ million ( 2 observations). Finally, in order to avoid biases due to observations with uncommon earnings or uncommon time variation in earnings, we also removed those observations lying in the first or last percentiles of the earnings or change in earnings distribution.
} 
job in the year of winning a lottery prize. As is shown in the table, the distribution of the prizes is very similar in the three samples.

Table 1: Distributions of prizes

\begin{tabular}{|c|c|c|c|c|c|}
\hline \multicolumn{6}{|l|}{ Prizes } \\
\hline \multicolumn{6}{|c|}{ (a) Original State Lottery data set } \\
\hline$[0, € 10,000]$ & 29,365 & 29,435 & 29,441 & 29,473 & 117,714 \\
\hline$(€ 10,000 ; € 100,000]$ & 262 & 265 & 262 & 229 & 1,018 \\
\hline$>€ 100,000$ & 106 & 33 & 30 & 31 & 200 \\
\hline Total & 29,733 & 29,733 & 29,733 & 29,733 & 118,932 \\
\hline \multicolumn{6}{|c|}{ (b) After merging with demographic and labor market data } \\
\hline$[0, € 10,000]$ & 18,158 & 18,205 & 18,208 & 18,236 & 72,807 \\
\hline$(10,000 ; € 100,000]$ & 163 & 161 & 164 & 135 & 623 \\
\hline$>€ 100,000$ & 69 & 24 & 17 & 19 & 129 \\
\hline Total & 18,390 & 18,390 & 18,390 & 18,390 & 73,560 \\
\hline \multicolumn{6}{|l|}{ (c) Final sample } \\
\hline$[0, € 10,000]$ & 8,953 & 8,566 & 8,727 & 8,836 & 35,082 \\
\hline$(€ 10,000 ; € 100,000]$ & 100 & 93 & 95 & 72 & 360 \\
\hline$>€ 100,000$ & 46 & 18 & 7 & 12 & 83 \\
\hline Total & 9,099 & 8,677 & 8,829 & 8,920 & 35,525 \\
\hline
\end{tabular}

\subsection{Summary statistics}

Our aim is to study the effect of lottery wins on yearly labor earnings and employment in the year of the lottery win and in subsequent years. Our observed time window covers four years, from 2005 until 2008. Our main analysis will be based on the estimation of four equations, each characterized by a different moment in which the employment outcomes are measured after lottery participation. More in detail, we estimate the impact of the lottery prize on labor earnings or employment status in the year of the lottery win and one, two and three calendar years later. The more we look ahead, the smaller the number of observations.

Table 2 reports the number of observations and the summary statistics of the variables used in the empirical analysis. The first column displays summary statistics of the sample we used to study the impact of yearly lottery prizes on current yearly earnings $(T=0)$. This is the largest sample, as it covers all four years. The subsequent three columns report descriptive statistics for later years $(T=1,2,3)$. In the extreme case in which we study the effect three years ahead, we are left with a cross-section: individuals winning prizes in 2005 whose earnings are observed in 2008. The explanatory variables can be split into time-constant and time-varying covariates. Gender and nationality (whether Dutch or not) are the time-constant regressors. The time-varying covariates (age, the number of children in the household, and being single or not) are measured at time $t$ of lottery participation, with $t=2005, \cdots, 2008$. The average yearly gross earnings in the full sample are $€ 37,093$. In a year, lottery subscribers spend on average $€ 224$ and win $€ 128$. The average age of players is 45 years, $32 \%$ of the players is female, and $21 \%$ is single (the remaining $79 \%$ lives in a couple). People with Dutch nationality represent 
almost $97 \%$ of the sample, and on average there is one child in the lottery players' household. Compared to the Dutch population in 2005 (18 years and older), our sample has about the same average labor earnings per household, the same number of children per household, and the same age. Our sample has a substantial lower share of females, non-Dutch and singles than the Dutch population had in 2005 (see Table A.2 in Appendix B).

Table 2: Summary statistics

\begin{tabular}{|c|c|c|c|c|c|c|c|c|}
\hline & \multicolumn{2}{|c|}{$T=0$} & \multicolumn{2}{|c|}{$\bar{T}=1$} & \multicolumn{2}{|c|}{$T=2$} & \multicolumn{2}{|c|}{$T=3$} \\
\hline & Mean & St. dev. & Mean & St. dev. & Mean & St. dev. & Mean & St. dev. \\
\hline Labor earnings in $t+T(€)$ & $37,093.270$ & $21,778.830$ & $37,813.990$ & $26,790.740$ & $37,513.550$ & $27,058.810$ & $36,938.670$ & $27,016.540$ \\
\hline Lottery wins in $t(€)$ & 127.751 & $16,113.860$ & 108.654 & $2,276.806$ & 107.312 & $2,622.658$ & 101.341 & $2,847.628$ \\
\hline Lottery expenditures in $t(€)$ & 224.168 & 166.175 & 220.505 & 166.867 & 220.778 & 162.866 & 218.422 & 155.677 \\
\hline Female & 0.322 & 0.467 & 0.323 & 0.468 & 0.318 & 0.466 & 0.315 & 0.465 \\
\hline Age in $t$ (years) & 45.271 & 9.540 & 44.706 & 9.608 & 44.537 & 9.572 & 44.390 & 9.574 \\
\hline$\#$ children in $t$ & 0.945 & 1.052 & 0.952 & 1.054 & 0.954 & 1.058 & 0.957 & 1.062 \\
\hline Dutch & 0.969 & 0.173 & 0.968 & 0.175 & 0.969 & 0.173 & 0.970 & 0.170 \\
\hline Single in $t$ & 0.205 & 0.404 & 0.201 & 0.401 & 0.198 & 0.398 & 0.198 & 0.398 \\
\hline 2005 & 0.263 & 0.440 & \multicolumn{2}{|c|}{ - } & \multicolumn{2}{|c|}{ - } & \multicolumn{2}{|c|}{-} \\
\hline 2006 & 0.246 & 0.430 & 0.332 & 0.471 & \multicolumn{2}{|c|}{ - } & \multicolumn{2}{|c|}{ - } \\
\hline 2007 & 0.245 & 0.430 & 0.331 & 0.470 & 0.498 & 0.500 & \multicolumn{2}{|c|}{ - } \\
\hline 2008 & 0.246 & 0.431 & 0.337 & 0.473 & 0.502 & 0.500 & 1.000 & 0.000 \\
\hline Observations & \multicolumn{2}{|c|}{35,525} & \multicolumn{2}{|c|}{28,062} & \multicolumn{2}{|c|}{18,499} & \multicolumn{2}{|c|}{9,182} \\
\hline
\end{tabular}

Notes: Labor earnings are gross earnings. "\# children" stands for the number of children in the household. Sample weights are used to take into account that individuals winning less than $€ 1,000$ are a $1 \%$ random draw from the population of small-prize lottery winners. The time varying covariates are measured at the time $t$ of lottery participation, with $t=2005, \cdots, 2008$. All the monetary values are in real terms $(\mathrm{CPI}$ in $2005=$ 100).

Table 3 reports mean labor earnings and employment rates in the three categories of lottery prizes: small (smaller than $€ 10,000$ ), medium (between $€ 10,000$ and $€ 100,000$ ), and large (more than $€ 100,000$ ). This table provides a raw indication of the presence of a relationship between lottery prizes and labor supply, unconditional on individual characteristics. For example, two years after lottery participation $(T=2)$, large-prize winners earn about $€ 1,750$ less than small-prize winners. Three years later, large-prize winners earn about $€ 106$ less than small-prize winners. Also, the employment rate of large-prize winners is about 5 percentage points lower than the one of small-prize winners three years after lottery participation. If we look at $T=0$, we see that large-prize winners earn almost $€ 1,800$ less than small-prize winners, suggesting that they work less in the year of winning the large prize. These statistics indicate that lottery prizes might induce some labor supply response, either immediately or after a while. There is also quite some variation in the data that seems to be unrelated to prize winning. For example, average labor earnings in each of the categories are higher in $T=1$ than in $T=0$. Furthermore, the unconditional relations might be biased due to the presence of omitted variables, especially ticket expenditures. The ticket expenditures might indeed be correlated to both earnings at the time of winning - those who are richer might buy more (or less) tickets - and the probability of winning small and medium prizes. In the empirical analysis, we will control for ticket expenditures to solve for the omitted variables problem, as well as for a set of individual and family characteristics potentially affecting labor earnings and employment. 
Table 3: Labor supply in $T$ by size of lottery prize (standard deviation in parenthesis)

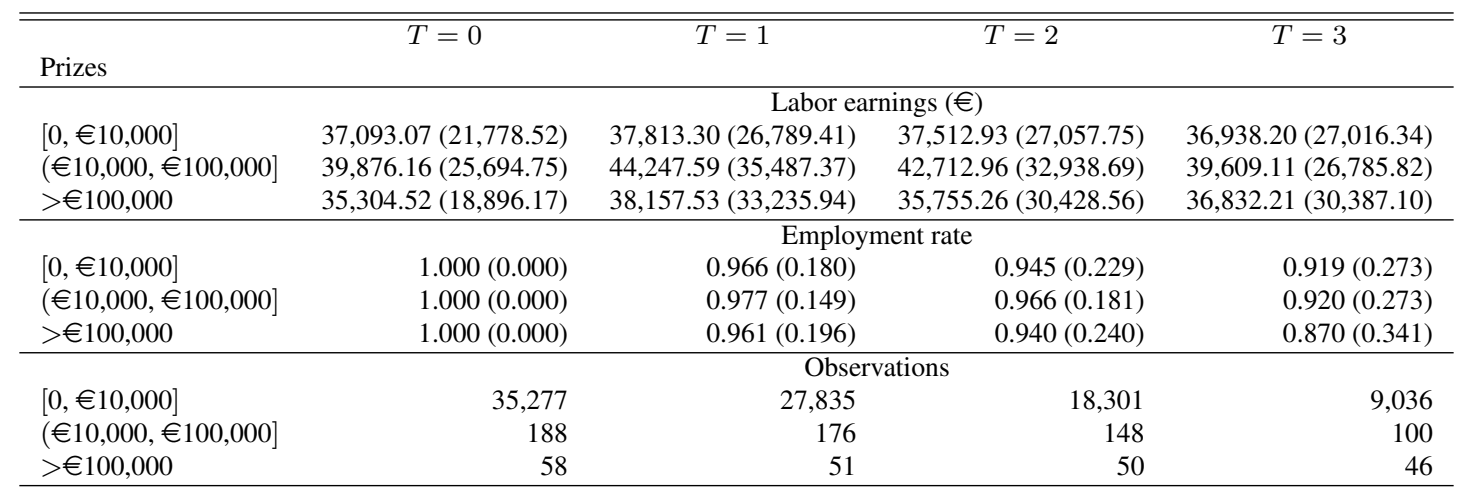

Notes: Standard deviations are in parentheses. Labor earnings are yearly gross labor earnings. Sample weights are used to take into account that individuals winning less than $€ 1,000$ are a $1 \%$ random draw from the population of small-prize lottery winners. Since we focus on individuals who are employed in the year they win the lottery prize, the employment rate at $T=0$ is equal to 1 by construction. All the monetary values are in real terms (CPI in $2005=100$ ).

\section{Econometric analysis}

\subsection{Model}

We are interested in quantifying the impact of income shocks at the extensive margin and the intensive margin of labor supply. In order to quantify the impact at the intensive margin of labor supply, we study the effect of winning lottery prizes on yearly salaried earnings. At the extensive margin of labor supply, we focus on whether or not the individual's earnings become zero (i.e. the individual disappears from the SSB Jobs database) in the years after the lottery participation.

Under the assumption that leisure time is not an inferior good, we expect a negative impact of winning the lottery on labor supply only for individuals who are employed at the time of winning, and not so for individuals who are not employed at the time of winning. This is the main reason why in our benchmark model, we focus on individuals who are employed at the time of winning a prize. We denote by $t$ the year in which individuals participate in the lottery, with $t=2005, \ldots, 2008$. Furthermore, we denote by $p_{i t}$ the lottery prize of individual $i$ in year $t$. Finally, we denote by $y_{i t+T}$ the outcome variable, where $T$ indicates how many years after the lottery win the outcome variable is measured. When we study the impact at the intensive margin, $y_{i t+T}$ will indicate the yearly salaried gross earnings $T$ years after lottery participation, with $T=0,1,2,3$. When we look at the effect at the extensive margin, $y_{i t+T}$ will be a dummy indicator equal to one if individual $i$ was an employee in year $t+T$, and zero otherwise. At the extensive margin, $T$ does not take value 0 , since in the year of lottery participation everybody is in salaried employment by sample construction. Our main equation for labor market outcome $y_{i t+T}$ is:

$$
y_{i t+T}=\mathbf{x}_{i t}^{\prime} \boldsymbol{\beta}_{T}+p_{i t} \delta_{T}+u_{i t+T}
$$

where $u_{i t+T}$ is the error term, $\mathbf{x}_{i t}$ is a set of predetermined regressors measured at the time $t$ 
of the lottery participation, and $\delta_{T}$ is the linear effect of the lottery prize on the labor market outcome $T$ years ahead. ${ }^{15}$ Ordinary Least Squares (OLS) estimation of Eq. (1) returns unbiased estimates of $\boldsymbol{\delta}_{T}$ if the individual lottery win is uncorrelated to the error term conditional on $\mathbf{x}_{i t} \cdot{ }^{16}$ This is the case if there are no other relevant variables correlated with the labor market outcome variable and lottery prizes. Among the set of control variables we have ticket expenditures, age, squared age, number of children in the household, nationality, gender, whether single or living in a couple, year dummies, and the constant.

Importantly, the year dummies capture the time fixed effects. Each year, the Dutch State Lottery slightly changes the prize structure, influencing thereby the realization of the prize variable. Moreover, gross salaries might also vary each year due to, for instance, the business cycle, changes in labor market conditions, new contractual agreements between unions and firms, etc. Not introducing year fixed effects among the regressors may lead to spurious correlation between yearly lottery prizes and yearly gross salaries.

As indicated in the introduction, winning the lottery is a random event for lottery participants. However, participating in the lottery and the amount of money individuals spend on buying lottery tickets might be non-random events. Therefore, controlling for ticket expenditures is very important. The probability of winning prizes (especially small prizes) can be affected by the number of purchased lottery tickets and, hence, by how much is spent on lottery tickets. Ticket expenditures can in turn be (positively) correlated with earnings. So, if we do not control for ticket expenditures and if there is positive correlation between earnings (or the probability of being at work) and tickets expenditures, OLS will overestimate the impact of lottery prizes on employment earnings (employment probability). Luckily, we have information on individual yearly expenditures on lottery tickets and we can include the variable in the model specification.

In summary, our identification strategy relies on the prize variation between lottery subscribers, conditional on ticket expenditures and time fixed effects (and individual characteristics). Henceforth, it is based on the comparison of yearly gross earnings of subscribers who were randomly assigned yearly lottery prizes, conditional on ticket expenditures, time fixed effects, and individual characteristics. In order to shed more light on the robustness of the random assignment of lottery prizes, we regressed, in the spirit of Imbens et al. (2001), the yearly lottery prizes at time $t$ on the yearly ticket expenditures at time $t$, the time fixed effects, and the individual characteristics at time $t$ (gender, age, age squared, number of children in the household, nationality, and being single). If the random assignment assumption holds, the individual characteristics should not be able to predict the lottery prizes. This is exactly what we find:

\footnotetext{
${ }^{15}$ The impact of lottery prizes on labor market outcomes is assumed to be linear. In a sensitivity analysis we depart from the linear assumption and we assume that lottery prizes enter the labor market outcome equation through a piecewise continuous spline function with two knots, respectively at $€ 10,000$ (which is about the 99th percentile of the lottery prize distribution) and at $€ 100,000$. Since we could not reject the null hypothesis of no slope change at the knots both when using the full sample and when splitting the sample in men and women, in what follows we only report parameter estimates based on the linear specification of Eq. (1).

${ }^{16}$ It may be that the presence of a big "Jackpot" might convince some people to subscribe to the lottery. However, even if this is the case, winning the lottery is not correlated to the error term in our regressions.
} 
testing for the joint and the individual significance of the coefficients of the individual characteristics does not lead to the rejection of the null hypothesis of a zero effect (see Appendix D, Table A.5). This provides support for the random assignments of the lottery prizes, conditional on ticket expenditures and year fixed effects.

As said, we select employed individuals at the time of lottery participation and, therefore, we estimate the impact of lottery wins on future labor market outcomes conditional on being at work in the year of lottery earnings. In a sensitivity analysis, we also estimate the unconditional effect by enlarging the sample to individuals who did not have labor earnings at the time of lottery participation.

\subsection{Main results}

Table 4 presents the main parameter estimates. ${ }^{17}$ The table shows that already in the year of winning the prize there is a significant negative effect on labor earnings. The magnitude of -0.005 implies that if an individual wins $€ 100,000$, earnings go down by an amount of $€ 50$. In later years, the effect is larger in size. This makes sense, because about half of the individuals won the lottery in the second half of the year. In addition, it may be that if individuals react to winning the lottery they need some time to do so. In the first year after winning a lottery prize of $€ 100,000$ ( $T=1$ ) earnings go down by an amount of $€ 1,160,2$ years later this is $€ 1,640$, and after 3 years it is $€ 1,770$. The earnings effects thus seem to persist.

The bottom part of Table 4 shows that there is no significant effect of lottery prizes on the probability to be employed. The parameter estimate of -0.076 implies that a lottery prize of $€ 100,000$ reduces the probability to be employed with 0.76 percentage points, but this is not significantly different from zero. Apparently, individuals adjust their labor supply in response to winning a lottery but they do not withdraw from the labor market. We conclude that lottery prizes affect earnings but not employment status. This suggests that lottery prizes affect the intense margin of labor supply and not the extensive margin.

Table 4: Lottery prize effects conditional on labor market participation at the time of lottery win

\begin{tabular}{|c|c|c|c|c|c|c|c|c|}
\hline & \multicolumn{2}{|c|}{$T=0$} & \multicolumn{2}{|c|}{$T=1$} & \multicolumn{2}{|c|}{$\bar{T}=2$} & \multicolumn{2}{|c|}{$T=3$} \\
\hline \multicolumn{2}{|c|}{ Dependent variable: Labor earnings } & \multirow[b]{2}{*}{$(0.002) * *$} & \multirow[b]{2}{*}{-0.116} & \multirow[b]{2}{*}{$(0.069) *$} & \multirow[b]{2}{*}{-0.164} & \multirow[b]{2}{*}{$(0.058)^{* * *}$} & \multirow[b]{2}{*}{-0.177} & \multirow[b]{2}{*}{$(0.062) * * *$} \\
\hline Prize amount $/ 10$ & -0.005 & & & & & & & \\
\hline \multicolumn{9}{|c|}{ Dependent variable: Employment status } \\
\hline Prize amount & - & - & -0.076 & $(0.108)$ & -0.063 & $(0.125)$ & -0.189 & $(0.202)$ \\
\hline Number of observations & \multicolumn{2}{|c|}{35,525} & \multicolumn{2}{|c|}{28,062} & \multicolumn{2}{|c|}{18,499} & \multicolumn{2}{|c|}{9,182} \\
\hline
\end{tabular}

Notes: Sample weights are used to take into account that individuals winning less than $€ 1,000$ are a $1 \%$ random draw from the population of small lottery winners. Standard errors are reported in parenthesis and are robust to heteroskedasticity and serial correlation. Coefficients and standard errors in the regressions of employment status are multiplied by $1.0 \mathrm{e}+06$ for the sake of readability. The full set of estimation results are reported in Appendix C, Table A.3.

Table 5 reports the results from unconditional regressions, that is, from regressions where

\footnotetext{
${ }^{17}$ Appendix $\mathrm{C}$ gives an overview of all parameter estimates, including the control variables.
} 
individuals are no longer required to be employed in the year of winning a lottery prize. We expected that including these individuals would decrease potential effects of winning a lottery prize, because individuals who initially are without a job are not supposed to enter the labor market because of winning the lottery. This is indeed what we find. The (absolute) magnitudes of the parameter estimate are smaller and no longer significant in the year of winning the prize or in the first year thereafter. The effects remain significant, however, in the second and third year after winning a lottery prize.

Table 5: Lottery prize effects unconditional on labor market participation at the time of lottery win

\begin{tabular}{|c|c|c|c|c|c|c|c|c|}
\hline & \multicolumn{2}{|c|}{$\bar{T}=0$} & \multicolumn{2}{|c|}{$\bar{T}=1$} & \multicolumn{2}{|c|}{$\bar{T} \bar{T}=2$} & \multicolumn{2}{|c|}{$T=3$} \\
\hline Dependent variable: Labor e & ings & & & & & & & \\
\hline Prize amount/10 & -0.001 & $(0.003)$ & -0.070 & $(0.051)$ & -0.113 & $(0.042)^{* * *}$ & -0.118 & $(0.044)^{* * *}$ \\
\hline \multicolumn{9}{|c|}{ Dependent variable: Employment status } \\
\hline Prize amount & - & - & -0.106 & $(0.106)$ & -0.119 & $(0.100)$ & -0.195 & $(0.122)$ \\
\hline Number of observations & \multicolumn{2}{|c|}{45,328} & \multicolumn{2}{|c|}{35,245} & \multicolumn{2}{|c|}{23,357} & \multicolumn{2}{|c|}{11,644} \\
\hline
\end{tabular}

Notes: Sample weights are used to take into account that individuals winning less than $€ 1,000$ are a $1 \%$ random draw from the population of small lottery winners. Standard errors are reported in parenthesis and are robust to heteroskedasticity and serial correlation. Coefficients and standard errors in the regressions of employment status are multiplied by $1.0 \mathrm{e}+06$ for the sake of readability. The full set of estimation results are reported in Appendix C, Table A.4.

\subsection{Heterogeneity}

In this section, we slice up the data in several ways, and focus on the effect of lottery prizes on labor market behavior of different types of individuals. In particular, we investigate to what extent there is heterogeneity in effects according to gender, age (up to 50 versus older than 50), family status (non-single versus single), earnings (below versus above the median), and parental status (no children versus children). Results of regressions for these subgroups are presented in Table 6. We first discuss the results related to labor earnings, reported in the upper part of the table.

First, Table 6 shows that although labor earnings of male players tend to go down more as lottery prizes increase than earnings of female players, gender differences are not significant.

Second, Table 6 shows that the negative effects of lottery prizes on labor earnings are driven by individuals who are below age 50 . That is, only for individuals below age 50 the effects are significant, and not so for individuals who are older than 50. To illustrate, a prize of $€ 100,000$ reduces annual earnings of individuals below age 50 by about $€ 2,000$, on average. With annual earnings of about $€ 40,000$ this implies that working hours are reduced with about 2 hours per week or about 2 to 3 weeks per year. Alternatively, we might conclude that an increase of unearned income of $€ 100,000$ reduces earnings with a short-run marginal propensity to consume leisure of approximately 2 percent. However, the effect of a one-time positive shock to non-labor income affects earnings for several years, so the long-run marginal propensity to consume leisure is substantially higher than the short-run marginal propensity to consume 
leisure. Apparently, to be able to smooth labor supply, individuals and households save a substantial part of their lottery wins.

Third, Table 6 shows the parameter estimates depending on the family status, obtained by introducing an interaction term between lottery prize and a dummy variable for being single. The main effect is negative but never significantly different from zero. The interaction term is also negative, but except in $T=2$, not significantly different from zero. Wald tests for the sum of the parameter estimates, however, indicate that the overall effect is significantly negative. So, the negative earnings effect of winning a lottery prize is located among singles and is not significantly different from zero for individuals who live together with a partner.

Fourth, we report results from regressions that include an interaction term between the lottery prize and a dummy variable that indicates whether the individual earns more than the median income. Here, results are somewhat mixed. In years $T=0$ and $T=3$, the negative effect of lottery prizes on labor earnings is mostly driven by high-income individuals, but not so in the other two years.

Finally, we report estimation results from regressions augmented by an interaction term between lottery prize and a dummy variable indicating the presence of children. In all four specifications, the parameter of the interaction term is positive with a magnitude that is about the same as the negative main effect. Moreover, the sum of the two parameter is never significantly different from zero. Compared to the other estimates, the parameter estimate of individuals without children is the largest in magnitude, and most consistent across the four specifications. This suggests that the negative effects of lottery prizes on labor earnings are fully driven by individuals without children.

The lower part of Table 6 reports the results from regressions where the dependent variable refers to being employed or not. Overall, we do not find an effect of lottery prizes on employment for any of the subgroups. The only effect that turns out to be significant is the effect for high-income individuals. For them, we find a negative effect on employment status after 3 years: winning $€ 100,000$ decreases the employment rate by 8 percentage points. ${ }^{18}$

\subsection{Family spillovers}

In this section we investigate in the spirit of Cesarini et al. (2015) whether there are "spillover" effects from the spouse in a family winning a prize. In particular, the question is whether if an individual wins a lottery prize the partner reduced his or her earnings. The upper part of Table 7 presents the parameter estimates. ${ }^{19}$ We find no lasting effects from lottery prizes won by the spouse on individuals' labor earnings. Apart from a small significant effect in the year in which the lottery prize was won none of the parameter estimates differs significantly from zero. This

\footnotetext{
${ }^{18}$ High-earnings individuals may have high savings so that, when when winning a prize of $€ 100,000$, some of them stop working at least for a while. Note that also after 2 years there is a significant ( $10 \%$ level) negative effect for high-income individuals. For females after 1 year, and couples after 2 years there are significant positive effects on employment status but the magnitude of these effects is small.

${ }^{19}$ Given that effects at the extensive margin are not significant, we only report results on labor earnings.
} 
Table 6: Heterogeneity of lottery prizes effects

\begin{tabular}{|c|c|c|c|c|c|c|c|c|}
\hline & \multicolumn{2}{|c|}{$T=0$} & \multicolumn{2}{|c|}{$T=1$} & \multicolumn{2}{|c|}{$T=2$} & \multicolumn{2}{|c|}{$T=3$} \\
\hline \multicolumn{9}{|l|}{ Dependent variable: Labor earnings } \\
\hline \multicolumn{9}{|l|}{$a$. By gender } \\
\hline Prize amount/10 if male & -0.012 & $(0.012)$ & -0.140 & $(0.085)^{*}$ & -0.185 & $(0.073)^{* *}$ & -0.204 & $(0.105)^{*}$ \\
\hline Prize amount/10 if female & -0.002 & $(0.001)^{* *}$ & -0.119 & $(0.088)$ & -0.164 & $(0.098)^{*}$ & -0.153 & $(0.097)$ \\
\hline Wald test difference, $p$-value & \multicolumn{2}{|c|}{0.413} & \multicolumn{2}{|c|}{0.864} & \multicolumn{2}{|c|}{0.866} & \multicolumn{2}{|c|}{0.723} \\
\hline \multicolumn{9}{|l|}{$b$. By age } \\
\hline Prize amount $/ 10$ & -0.007 & $(0.004)^{*}$ & -0.221 & $(0.077)^{* * *}$ & -0.227 & $(0.058)^{* * *}$ & -0.190 & $(0.062)^{* * *}$ \\
\hline Prize amount $/ 10 \times$ Older than 50 & 0.006 & $(0.005)$ & 0.697 & $(0.404)^{*}$ & 0.383 & $(0.245)$ & 0.341 & $(0.689)$ \\
\hline Wald test sum of coeff., $p$-value & \multicolumn{2}{|c|}{0.883} & \multicolumn{2}{|c|}{0.213} & \multicolumn{2}{|c|}{0.489} & \multicolumn{2}{|c|}{0.8252} \\
\hline \multicolumn{9}{|l|}{ c. By family status } \\
\hline Prize amount $/ 10$ & -0.004 & $(0.007)$ & -0.014 & $(0.092)$ & -0.079 & $(0.086)$ & -0.107 & $(0.090)$ \\
\hline Prize amount $/ 10 \times$ Single & -0.001 & $(0.007)$ & -0.410 & $(0.290)$ & -0.302 & $(0.167)^{*}$ & -0.150 & $(0.126)$ \\
\hline Wald test sum of coeff., $p$-value & \multicolumn{2}{|c|}{0.011} & \multicolumn{2}{|c|}{0.099} & \multicolumn{2}{|c|}{0.003} & \multicolumn{2}{|c|}{0.001} \\
\hline \multicolumn{9}{|l|}{$d$. By earnings } \\
\hline Prize amount $/ 10$ & -0.002 & $(0.003)$ & -0.178 & $(0.081)^{* *}$ & -0.181 & $(0.062)^{* * *}$ & -0.051 & $(0.045)$ \\
\hline Prize amount $/ 10 \times$ high earnings & -0.007 & $(0.004)$ & 0.164 & $(0.151)$ & 0.066 & $(0.156)$ & -0.309 & $(0.169)^{*}$ \\
\hline Wald test sum of coeff., $p$-value & \multicolumn{2}{|c|}{0.002} & \multicolumn{2}{|c|}{0.906} & & 405 & & 02 \\
\hline$e$. By parental status & & & & & & & & \\
\hline Prize amount $/ 10$ & -0.225 & $(0.108)^{* *}$ & -0.339 & $(0.181)^{*}$ & -0.256 & $(0.126)^{* *}$ & -0.275 & $(0.113)^{* *}$ \\
\hline Prize amount $/ 10 \times$ presence of kids & 0.222 & $(0.108)^{* *}$ & 0.367 & $(0.229)$ & 0.166 & $(0.178)$ & 0.207 & $(0.174)$ \\
\hline Wald test sum of coeff., $p$-value & & 58 & & 809 & & 398 & & 887 \\
\hline Dependent variable: Employment status & & & & & & & & \\
\hline$a$. By gender & & & & & & & & \\
\hline Prize amount if male & - & - & -0.124 & $(0.140)$ & 0.052 & $(0.034)$ & -0.025 & $(0.112)$ \\
\hline Prize amount if female & - & - & 0.064 & $(0.038)^{*}$ & -0.365 & $(0.334)$ & -0.367 & $(0.336)$ \\
\hline Wald test difference, $p$-value & & & & 195 & & 214 & & 334 \\
\hline$b$. By age & & & & & & & & \\
\hline Prize amount & & & -0.134 & $(0.126)$ & -0.118 & $(0.142)$ & -0.212 & $(0.202)$ \\
\hline Prize amount $\times$ Older than 50 & & & 0.390 & $(0.264)$ & 0.329 & $(0.253)$ & 0.603 & $(0.839)$ \\
\hline Wald test sum of coeff., $p$-value & & - & & 257 & & 301 & & 528 \\
\hline c. By family status & & & & & & & & \\
\hline Prize amount & & & 0.058 & $(0.038)$ & 0.083 & $(0.044)^{*}$ & 0.045 & $(0.105)$ \\
\hline Prize amount $\times$ Single & & & -0.535 & $(0.341)$ & -0.517 & $(0.347)$ & -0.504 & $(0.371)$ \\
\hline Wald test sum of coeff., $p$-value & & - & & 152 & & 203 & & 190 \\
\hline$d$. By earnings & & & & & & & & \\
\hline Prize amount & & & -0.116 & $(0.204)$ & 0.150 & $(0.060)^{* *}$ & 0.066 & $(0.065)$ \\
\hline Prize amount $\times$ high earnings & & & 0.086 & $(0.210)$ & -0.481 & $(0.258)^{*}$ & -0.863 & $(0.218)^{* * *}$ \\
\hline Wald test sum of coeff., $p$-value & & - & & 378 & & 184 & & 000 \\
\hline e. By parental status & & & & & & & & \\
\hline Prize amount & & & -0.261 & $(0.244)$ & 0.069 & $(0.053)$ & 0.043 & $(0.079)$ \\
\hline Prize amount $\times$ presence of kids & & & 0.303 & $(0.248)$ & -0.236 & $(0.215)$ & -0.461 & $(0.347)$ \\
\hline Wald test sum of coeff., $p$-value & & - & & 159 & & 417 & & 211 \\
\hline Number of observations & & 525 & & 062 & & 499 & & 182 \\
\hline
\end{tabular}

Notes: We report $p$-values related to Wald tests that to the significance of either the difference in estimated coefficient between male and female players, or to the sum of the coefficients: * significant at $10 \%$; ** significant at $5 \%$; *** significant at $1 \%$. Sample weights are used to take into account that individuals winning less than $€ 1,000$ are a $1 \%$ random draw from the population of small lottery winners. Standard errors are reported in parenthesis and are robust to heteroskedasticity and serial correlation. Coefficients and standard errors in the regressions of employment status are multiplied by $1.0 \mathrm{e}+06$ for the sake of readability 
is in line with our earlier finding that only singles seem to respond to lottery prize winnings.

Next, we sum the amount of lottery prizes won in each individual's family, that is, by oneself and the spouse, and study whether there is an effect on labor earnings of the individual. The expectation was that the results would be very similar to our main results, given that the prize won in an individual's family consists for a large part by the prize personally won by the individual (and for singles, these two prize amount are, of course, equal). The lower part of Table 7 presents the regression results. As expected, the findings are much in line with our earlier findings that the effect of lottery prizes is significantly negative in subsequent years.

Table 7: Family lottery prize effects

\begin{tabular}{|c|c|c|c|c|}
\hline & $\bar{T}=0$ & $T=1$ & $\bar{T}=2$ & $\bar{T}=3$ \\
\hline$a . \mathrm{E}$ & $(0.003$ & $(0.055)$ & $(0.053)$ & $(0.096)$ \\
\hline Number of observations & 22,324 & 16,029 & 9,882 & 4,661 \\
\hline b. Effect on family earnin & -0.008 & $(0.109)^{\text {** }}$ & $(0.117)^{* *}$ & $(0.117)$ \\
\hline Number of observations & 35,605 & 27,246 & 17,417 & 8,376 \\
\hline
\end{tabular}

Notes: The dependent variable is the amount of labor earnings. * significant at $10 \% ; * *$ significant at $5 \%$; *** significant at $1 \%$. Sample weights are used to take into account that individuals winning less than $€ 1,000$ are a $1 \%$ random draw from the population of small lottery winners. Standard errors are reported in parenthesis and are robust to heteroskedasticity and serial correlation.

\section{Conclusions}

When interpreting the results of our empirical analysis, the labor market situation in the Netherlands needs to be taken into account. In a labor market with high unemployment, employed individuals might not want to take the risk to temporary withdraw from the labor market for fear of having great difficulties to find a job later on. This is not the case in the Netherlands where in the period of analysis unemployment rates were low. According to OECD statistics, over the period of analysis the average unemployment rate in the Netherlands ranged from 3 to 5 percent, well below the OECD average. And, as discussed in the introduction, in the Netherlands it is not so difficult to adjust labor supply along the intensive margin. Part-time work is quite common. ${ }^{20}$

We find that winning a lottery prize affects the intensive margin of labor supply and not the extensive margin. We also find that the effect is heterogeneous, i.e. for some groups of individuals the effects are present while other individuals do not seem to change their labor

\footnotetext{
${ }^{20}$ In the Netherlands part-time employment has increased a lot during the past decades. This increase is accompanied by changes in collective agreements between unions and employers and changes in labor law that made part-time jobs more attractive. Since the early 1990s protective provisions for part-time workers are included in collective agreements (Roeters and Craig, 2014). From 1990 to 1996 the percentage of firms with a part-time clause in the collective agreement increased from 23 to 70 percent (Visser et al., 2004). In the past, two labor laws have been important. The first one is the Prohibition of Discrimination by Working Hours Act, which came into effect on 1 November 1996. This law forbids employers to discriminate between workers on the basis of a difference in working hours. The second law is the Adjustment of Working Hours Act, which came into force June 2000. Under this law a request of a worker to modify his or her working hours must be granted by the employer, unless it would seriously harm business. Currently the majority of working women have a part-time job and high levels of job satisfaction (Booth and van Ours, 2013).
} 
market position even after winning a substantial lottery prize. Specifically, the lottery prize effects materialize among younger single individuals without children.

We can only speculate about the reasons why this is the case. First, older workers would have been likely to respond since the lottery prize could have made it possible for them to retire early. But we find no such effect. Perhaps even a substantial lottery prize is insufficient to cover the earnings loss of withdrawal from the labor force. In other words, too few winners of a substantial lottery prize were sufficiently close to the retirement age to identify the effect. Another explanation could be that to receive full pension benefits one needs to work at least 40 years. Therefore, retiring early comes at a cost of forgone retirement benefits and the incentive to work less is not so strong at the end of one's working life. Second, parents with young children might have seized the opportunity to reduce working hours and spend more time with their children. We find no such effect. It could be that they organized work and care efficiently. It could also be that the parents want to save money to finance a better education for their children later on in life. We note that conditional on the lottery prize, partnered individuals with children won a lower per capita prize than singles.

The effect of winning a lottery prize on earnings is present for several years. The longrun marginal propensity to consume leisure is substantially larger than the short-run marginal propensity. Most likely, to be able to smooth labor supply individuals and households save a substantial part of their lottery wins. Apparently, lottery winners on average decide to benefit from their prizes for several years in a row. They seem to reduce working hours but only by a few hours per week, or alternatively by taking more days off and taking longer holidays.

\section{References}

Arvey, R. D., Harpaz, I., and Liao, H. (2004). Work centrality and post-award work behavior of lottery winners. Journal of Psychology: Interdisciplinary and Applied, 138:404-420.

Booth, A. and van Ours, J. (2013). Part-time jobs: what women want? Journal of Population Economics, 26:263-283.

Brown, J. R., Coile, C. C., and Weisbenner, S. J. (2010). The effect of inheritance receipt on retirement. Review of Economics and Statistics, 92:425-434.

Cesarini, D., Lindqvist, E., Notowidigdo, M., and Östling, R. (2015). The effect of wealth on household labor supply: Evidence from Swedish lotteries. Mimeo.

Furaker, B. and Hedenus, A. (2009). Gambling windfall decisions: Lottery winners and employment behavior. Gaming Research \& Review Journal, 13:1-15.

Goodstein, R. (2008). The effect of wealth on labor force participation of older men. Discussion Paper University of North Carolina at Chapel Hill.

Hedenus, A. (2009). Time for work or time for family? Work-life balance after winning the lottery. World Leisure Journal, 51:27-38.

Hedenus, A. (2012). Who wants to work less? Significance of socio-economic status and 
work conditions for work commitment among Swedish lottery winners. Acta Sociologica, 55:335-350.

Hurd, M. D., Reti, M., and Rohwedder, S. (2009). The effect of large capital gains or losses on retirement. In Wise, D. A., editor, Develpments in the Economics of Aging, chapter 4, pages 127-163. National Bureau of Economic Research.

Imbens, G., Rubin, D., and Sacerdote, B. (2001). Estimating the effect of unearned income on labor earnings, savings, and consumption: Evidence from a survey of lottery players. American Economic Review, 91:778-794.

Jacob, B. A. and Ludwig, J. (2012). The effects of housing assistance on labor supply: Evidence from a voucher lottery. American Economic Review, 102:272-304.

Joulfaian, D. and Wilhelm, M. (1994). Inheritances and labor supply. Journal of Human Resources, 29:1205-1234.

Kaplan, H. R. (1987). Lottery winners: The myth and reality. Journal of Gambling Behavior, 3:168-178.

Keane, M. P. (2011). Labor supply and taxes: A survey. Journal of Economic Literature, 49:961-1075.

Kuhn, P., Kooreman, P., Soetevent, A. R., and Kapteyn, A. (2011). The own and social effects of an unexpected income shock: Evidence from the Dutch Postcode Lottery. American Economic Review, 101:2226-2247.

Roeters, A. and Craig, L. (2014). Part-time work, women's work-life conflict, and job satisfaction: a cross-national comparison of Australia, the Netherlands, Germany, Sweden, and the United Kingdom. International Journal of Comparative Sociology, 55:185-203.

Visser, J., Wilthagen, T., Beltzer, R., and Koot-van der Putte, E. (2004). The Netherlands: from atypicality to typicality. In Sciarra, S., Davies, P., and Freedland, M., editors, Employment Policy and the Regulation of Part-time Work in the European Union; A Comparative Analysis, pages 190-223. Cambridge, Cambridge University Press. 


\section{Appendix}

\section{A Prize structure of the State Lottery}

Table A.1: Prize structure of the State Lottery

\begin{tabular}{lcc}
\hline Prize amount & Correct letters/numbers & Number of combinations \\
\hline$€ 7,500,000$ & 8 & 1 \\
$€ 1,000,000$ & 8 & 1 \\
$€ 100,000$ & 8 & 10 \\
$€ 25,000$ & 8 & 10 \\
$€ 10,000$ & 8 & 20 \\
$€ 1,000$ & 5 & 5 \\
$€ 450$ & 5 & 7 \\
$€ 250$ & 5 & 7 \\
$€ 100$ & 5 & 8 \\
$€ 30$ & 2 & 3 \\
$€ 20$ & 1 & 1 \\
$€ 10$ & 1 & 1 \\
$€ 7.5$ & 1 & 2 \\
$€ 5$ & 1 & 1 \\
\hline
\end{tabular}

Notes: This table gives an overview of the current prize structure in the State Lottery. This prize structure has been relatively constant since 2005 .

\section{B Summary statistics of the Dutch population}

Table A.2: Summary statistics of the Dutch population

\begin{tabular}{lrr}
\hline \hline & Our sample $(T=0)$ & Dutch Population (year 2005) \\
\hline Labor earnings/primary income $(€)$ & 37,093 & 38,000 \\
Female & 0.32 & 0.50 \\
Age (years) & 45.3 & 46.9 \\
\# children & 0.95 & 1.04 \\
Dutch & 0.97 & 0.75 \\
Single & 0.21 & 0.35 \\
\hline Observations & 35,525 & $7,042,000$ \\
\hline
\end{tabular}

Notes: Labor earnings are gross earnings; primary earnings for the population include earnings and income from savings and profits; age population: average of population 18 years and older; "\# children" stands for the number of children in the household. All the monetary values are in real terms $(\mathrm{CPI}$ in $2005=100)$. The number of observations of the population refers to the number of households; there were 16.3 million inhabitants in total, of which 12.7 million were 18 years or older. Source: Statistics Netherlands 


\section{Full parameter estimates}

Table A.3: Full set of estimation results of the effect of lottery prizes on earnings conditional on labor market participation at the time of lottery participation

\begin{tabular}{|c|c|c|c|c|c|c|c|c|c|c|c|c|}
\hline & \multicolumn{3}{|c|}{$\bar{T}=0$} & \multicolumn{3}{|c|}{$T=1$} & \multicolumn{3}{|c|}{$T=2$} & \multicolumn{3}{|c|}{$T=3$} \\
\hline & Coeff. & & Std. Err. & Coeff. & & Std. Err. & Coeff. & & Std. Err. & Coeff. & & Std. Err. \\
\hline \multicolumn{13}{|c|}{ Dependent variable: Labor earnings } \\
\hline Prize amount & -0.0005 & ** & 0.0002 & -0.0116 & * & 0.0069 & -0.0164 & $* * *$ & 0.0058 & -0.0177 & $* * *$ & 0.0062 \\
\hline Ticket expenditure & 10.6808 & $* * *$ & 2.1467 & 11.5929 & $* * *$ & 2.6187 & 12.4920 & $* * *$ & 3.0141 & 1.0042 & $* * *$ & 0.3252 \\
\hline Female & $-17,490.6900$ & $* * *$ & 466.3933 & $-18,820.6300$ & **** & 530.8459 & $-18,578.7500$ & $* * *$ & 559.1594 & $-18,576.1400$ & $* * *$ & 605.6606 \\
\hline Age & $3,396.6180$ & $* * *$ & 214.3667 & $4,207.8120$ & $* * *$ & 255.2251 & $4,898.6990$ & $* * *$ & 268.6920 & $5,404.3550$ & $* * *$ & 293.4588 \\
\hline Age squared & $-3,744.2120$ & $* * *$ & 246.4054 & $-4,784.3760$ & $* * *$ & 301.8347 & $-5,730.9690$ & $* * *$ & 314.8177 & $-6,490.2370$ & $* * *$ & 341.1067 \\
\hline \# children & -96.7609 & & 264.5377 & 195.3832 & & 334.9954 & 211.1027 & & 345.6120 & 272.9508 & & 375.5471 \\
\hline Dutch & 224.4454 & & $1,424.7590$ & 77.6804 & & $1,648.3870$ & 507.3603 & & $1,735.5080$ & -297.6902 & & $1,942.1980$ \\
\hline Single & $-1,493.6390$ & $* * *$ & 551.1282 & $-2,100.0620$ & **** & 646.4357 & $-2,165.062$ & $* * *$ & 683.7948 & $-1,913.2930$ & $* *$ & 772.5419 \\
\hline \multicolumn{13}{|l|}{ Time dummies } \\
\hline 2006 & $1,651.2270$ & $* * *$ & 182.3413 & - & & - & - & & - & - & & - \\
\hline 2007 & $2,255.5350$ & $* * *$ & 219.3957 & $1,069.7310$ & $* * *$ & 243.3967 & 865.8302 & $* * *$ & 262.0515 & - & & - \\
\hline 2008 & $3,006.2610$ & $* * *$ & 239.3151 & $1,747.9100$ & $* * *$ & 279.7827 & - & & - & - & & - \\
\hline Constant & $-34,814.4400$ & $* * *$ & $4,654.1060$ & $-47,524.1200$ & **** & $5,394.0130$ & $-59,272.4800$ & $* * *$ & $5,675.0220$ & $-64,892.9100$ & $* * *$ & $6,252.1760$ \\
\hline$R^{2}$ & \multicolumn{3}{|c|}{0.1798} & \multicolumn{3}{|c|}{0.1466} & \multicolumn{3}{|c|}{0.1513} & \multicolumn{3}{|c|}{0.1642} \\
\hline \multicolumn{4}{|c|}{ Dependent variable: Employment status } & & & & & & & & & \\
\hline Prize amount & \multirow{2}{*}{\multicolumn{2}{|c|}{$\overline{-}$}} & - & $-7.59 \mathrm{e}-08$ & & $1.08 \mathrm{e}-07$ & $-6.33 \mathrm{e}-08$ & & $1.25 \mathrm{e}-07$ & $-1.89 \mathrm{e}-07$ & & $2.02 \mathrm{e}-07$ \\
\hline Ticket expenditure & & & - & $-4.98 \mathrm{e}-06$ & & $1.30 \mathrm{e}-05$ & $-7.80 \mathrm{e}-06$ & & $1.79 \mathrm{e}-05$ & $-1.68 \mathrm{e}-06$ & & $3.61 \mathrm{e}-06$ \\
\hline Female & \multicolumn{2}{|l|}{ - } & - & -0.0046 & & 0.0030 & -0.0068 & & 0.0053 & -0.0091 & & 0.0075 \\
\hline Age & \multicolumn{2}{|l|}{ - } & - & 0.0212 & $* * *$ & 0.0017 & 0.0356 & $* * *$ & 0.0030 & 0.0520 & $* * *$ & 0.0042 \\
\hline Age squared & \multirow{2}{*}{\multicolumn{2}{|c|}{-}} & - & -0.0266 & $* * *$ & 0.0020 & -0.0450 & $* * *$ & 0.0036 & -0.0662 & $* * *$ & 0.0050 \\
\hline \# children & & & - & -0.0028 & $* *$ & 0.0014 & -0.0040 & & 0.0026 & -0.0040 & & 0.0034 \\
\hline Dutch & \multirow{2}{*}{\multicolumn{2}{|c|}{$\begin{array}{c}- \\
-\end{array}$}} & - & 0.0152 & $*$ & 0.0084 & 0.0293 & $*$ & 0.0155 & 0.0353 & & 0.0219 \\
\hline Single & & & - & -0.0102 & $* * *$ & 0.0039 & -0.0128 & $*$ & 0.0069 & -0.0107 & & 0.0096 \\
\hline \multicolumn{13}{|l|}{ Time dummies } \\
\hline 2006 & \multicolumn{2}{|l|}{ - } & - & \multicolumn{2}{|l|}{ - } & - & \multicolumn{2}{|l|}{ - } & - & \multicolumn{2}{|l|}{ - } & - \\
\hline 2007 & \multirow{2}{*}{\multicolumn{2}{|c|}{-}} & - & 0.0084 & \multirow[t]{2}{*}{$* *$} & 0.0033 & \multicolumn{2}{|l|}{0.0038} & 0.0032 & \multirow{2}{*}{\multicolumn{2}{|c|}{ - }} & - \\
\hline 2008 & & & - & 0.0049 & & 0.0034 & - & & - & & & - \\
\hline Constant & - & & - & 0.5633 & **** & 0.0364 & 0.2720 & $* * *$ & 0.0633 & -0.0467 & & 0.0865 \\
\hline$R^{2}$ & & - & & & 0342 & & & 0617 & & & 0986 & \\
\hline Observations & & 5,525 & & & 1,548 & & & 8,499 & & &, 182 & \\
\hline
\end{tabular}


Table A.4: Full set of estimation results of the effect of lottery prizes on earnings unconditional on labor market participation at the time of lottery participation

\begin{tabular}{|c|c|c|c|c|c|c|c|c|c|c|c|c|}
\hline & \multicolumn{3}{|c|}{$T=0$} & \multicolumn{3}{|c|}{$T=1$} & \multicolumn{3}{|c|}{$T=2$} & \multicolumn{3}{|c|}{$\overline{T=3}$} \\
\hline & Coeff. & & Std. Err. & Coeff. & & Std. Err. & Coeff. & & Std. Err. & Coeff. & & Std. Err. \\
\hline \multicolumn{13}{|c|}{ Dependent variable: Labor earnings } \\
\hline Prize amount & -0.0001 & & 0.0003 & -0.0070 & & 0.0051 & -0.0113 & $* * *$ & 0.0042 & -0.0118 & $* * *$ & 0.0044 \\
\hline Ticket expenditure & 7.7295 & $* * *$ & 1.9490 & 9.0508 & $* * *$ & 2.1848 & 10.5684 & $* * *$ & 2.5931 & 0.8782 & $* * *$ & 0.2858 \\
\hline Female & $-16,356.7200$ & $* * *$ & 465.6229 & $-17,751.1100$ & ***** & 511.938 & $-17,575.7200$ & $* * *$ & 523.8985 & $-17,623.0800$ & $* * *$ & 552.2048 \\
\hline Age & $4,545.3610$ & $* * *$ & 197.8169 & $4,702.2750$ & **** & 221.0822 & $5,003.3600$ & $* * *$ & 229.7220 & $5,119.1580$ & $* * *$ & 243.6238 \\
\hline Age squared & $-5,389.6980$ & $* * *$ & 219.3921 & $-5,655.2970$ & **** & 252.3260 & $-6,108.1670$ & $* * *$ & 259.1158 & $-6,364.8060$ & $* * *$ & 272.6558 \\
\hline \# children & -838.6670 & $* * *$ & 275.5560 & -495.7804 & & 321.5599 & -469.6305 & & 327.9827 & -142.7552 & & 363.4288 \\
\hline Dutch & $2,150.7900$ & & $1,435.8450$ & $1,760.8970$ & & $1,570.0060$ & $1,501.9290$ & & $1,590.8880$ & 791.4118 & & $1,694.7850$ \\
\hline Single & $-1,579.4270$ & $* * *$ & 558.5043 & $-1,908.5800$ & ***** & 624.3195 & $-1,960.4000$ & $* * *$ & 641.6609 & $-1,394.0330$ & $* *$ & 692.9729 \\
\hline \multicolumn{13}{|l|}{ Time dummies } \\
\hline 2006 & $1,548.3570$ & $* * *$ & 153.8800 & - & & - & - & & - & - & & - \\
\hline 2007 & $2,499.1600$ & $* * *$ & 201.7898 & $1,155.7790$ & $* * * *$ & 194.6113 & 670.3128 & $* *$ & 207.2651 & - & & - \\
\hline 2008 & $3,202.1790$ & $* * *$ & 227.3566 & $1,976.5410$ & **** & 235.0985 & - & & - & - & & - \\
\hline Constant & $-59,205.4300$ & $* * *$ & $4,398.6180$ & $-58,528.7800$ & ***** & $4,795.6970$ & $-62,180.3400$ & $* * *$ & $4,990.1190$ & $-61,091.9300$ & $* * *$ & $5,339.4790$ \\
\hline$R^{2}$ & \multicolumn{3}{|c|}{0.1724} & \multicolumn{3}{|c|}{0.1512} & \multicolumn{3}{|c|}{0.1650} & \multicolumn{3}{|c|}{0.1814} \\
\hline \multicolumn{13}{|c|}{ Dependent variable: Employment status } \\
\hline Prize amount & \multicolumn{2}{|l|}{-} & - & $-1.06 \mathrm{e}-07$ & & $1.06 e-07$ & $-1.19 \mathrm{e}-07$ & & $1.00 e-07$ & $-1.95 e-07$ & & $1.22 \mathrm{e}-07$ \\
\hline Ticket expenditure & \multirow{2}{*}{\multicolumn{2}{|c|}{-}} & - & $-7.80 \mathrm{e}-06$ & & $2.23 \mathrm{e}-05$ & $1.78 \mathrm{e}-06$ & & $2.50 \mathrm{e}-05$ & $-4.91 \mathrm{e}-07$ & & $3.73 e-06$ \\
\hline Female & & & - & -0.0838 & **** & 0.0092 & -0.0835 & $* * *$ & 0.0096 & -0.0812 & $* * *$ & 0.0101 \\
\hline Age & \multicolumn{2}{|l|}{ - } & - & 0.0545 & **** & 0.0037 & 0.0626 & $* * *$ & 0.0040 & 0.0704 & $* * *$ & 0.0044 \\
\hline Age squared & \multicolumn{2}{|l|}{-} & - & -0.0740 & **** & 0.0042 & -0.0843 & $* * *$ & 0.0046 & -0.0946 & $* * *$ & 0.0050 \\
\hline \# children & \multicolumn{2}{|l|}{-} & - & -0.0194 & $* * * *$ & 0.0045 & -0.0159 & $* * *$ & 0.0047 & -0.0121 & $* *$ & 0.0051 \\
\hline Dutch & \multirow{2}{*}{\multicolumn{2}{|c|}{ - }} & - & 0.0452 & *** & 0.0228 & 0.0352 & & 0.0245 & 0.0347 & & 0.0262 \\
\hline Single & & & - & -0.0131 & & 0.0105 & -0.0091 & & 0.0113 & -0.0063 & & 0.0123 \\
\hline \multicolumn{13}{|l|}{ Time dummies } \\
\hline 2006 & \multicolumn{2}{|l|}{-} & - & \multicolumn{2}{|l|}{ - } & - & \multicolumn{2}{|l|}{ - } & - & \multicolumn{2}{|l|}{ - } & - \\
\hline 2007 & \multicolumn{2}{|l|}{-} & - & 0.0147 & **** & 0.0029 & 0.0038 & & 0.0029 & - & & - \\
\hline 2008 & \multicolumn{2}{|l|}{ - } & - & 0.0192 & \multirow[t]{2}{*}{ **** } & 0.0038 & - & & - & - & & - \\
\hline Constant & \multirow{2}{*}{\multicolumn{2}{|c|}{-}} & - & -0.0874 & & 0.0793 & -0.2335 & $* * *$ & 0.0872 & -0.3844 & $* * *$ & 0.0958 \\
\hline$R^{2}$ & & & & & 1204 & & & .1404 & & & 1654 & \\
\hline Observations & & 5,328 & & & 5,245 & & & 3,357 & & & 1,644 & \\
\hline
\end{tabular}




\section{Tests of random assignment of lottery prizes}

Table A.5 reports the estimation results of the equation for the lottery prizes. The covariates are those used in the benchmark model. They are measured in the same year of the lottery win. If the assumption of random assignment of lottery prizes holds, conditional on lottery expenditures and year fixed effects, the six personal covariates (gender, age, age squared, number of children, nationality, and being single) should not be individually and jointly significant in explaining the lottery prizes. We find that the coefficients of the personal covariates are never significantly different from zero, both individually and jointly. This provides support for the random assignments of the lottery prizes. The lottery expenditures are positively correlated to the lottery prizes: each euro invested in lottery tickets returns about $€ 0.47-€ 0.59$. Finally, the time fixed effects are important in explaining the lottery prizes. This is due to the fact the Dutch State Lottery changed the structure of the lottery prizes across years. The year dummies capture these shocks in the prize structure. These random assignment tests reject the null hypothesis, if we do not include the ticket expenditures and the year fixed effects among the regressors. ${ }^{21}$

Table A.5: Estimation results of the regression of lottery prizes on covariates

\begin{tabular}{|c|c|c|c|c|c|c|c|c|c|c|c|c|}
\hline Variables & \multicolumn{3}{|c|}{$T=0$} & \multicolumn{3}{|c|}{$T=1$} & \multicolumn{3}{|c|}{$T=2$} & \multicolumn{3}{|c|}{$T=3$} \\
\hline Ticket expenditures $(€)$ & 0.5896 & **** & 0.0913 & 0.4744 & $* * *$ & 0.0138 & 0.4815 & **** & 0.0230 & 0.4895 & $* * *$ & 0.0459 \\
\hline Female & 17.3308 & & 28.4523 & -0.6186 & & 4.0419 & -3.8822 & & 5.2122 & 1.8055 & & 9.2838 \\
\hline Age squared & -3.3678 & & 2.9708 & -1.6037 & & 2.0174 & -1.1033 & & 2.7400 & 2.8878 & & 4.8327 \\
\hline \# of children & 18.7400 & & 16.6067 & 0.4170 & & 2.1207 & 1.8517 & & 2.6938 & 1.0711 & & 2.9662 \\
\hline Dutch & 15.1067 & & 13.7898 & 3.7795 & & 4.4298 & 2.7066 & & 6.0024 & 4.1113 & & 9.4183 \\
\hline Single & 51.8505 & & 57.6564 & -1.2226 & & 5.5501 & 2.8365 & & 7.7753 & 8.7901 & & 14.5544 \\
\hline 2007 & 2.9726 & & 5.1082 & 10.2746 & $* *$ & 5.0501 & 10.3189 & $* *$ & 5.0493 & - & & - \\
\hline 2008 & 12.0366 & ** & 5.9103 & 9.5904 & $* *$ & 4.6623 & - & & - & - & & - \\
\hline Constant & -185.3320 & & 148.0632 & -21.8314 & & 42.8771 & -11.5811 & & 60.5723 & 76.1089 & & 108.1510 \\
\hline Number of observations & \multicolumn{3}{|c|}{35,525} & \multicolumn{3}{|c|}{28,062} & \multirow{2}{*}{\multicolumn{3}{|c|}{18,499}} & \multirow{2}{*}{\multicolumn{3}{|c|}{9,182}} \\
\hline$R^{2}$ & \multicolumn{3}{|c|}{0.0000} & \multirow{2}{*}{\multicolumn{3}{|c|}{0.0012}} & \multirow{2}{*}{\multicolumn{3}{|c|}{0.0009}} & & & 0.0007 \\
\hline \multicolumn{7}{|c|}{$F$-test of joint significance of all the covariates } & & & & & & \\
\hline & \multicolumn{3}{|c|}{$\begin{array}{l}\quad p \text {-value }=0.000 \\
\text { of individual characteristics: female, }\end{array}$} & \multicolumn{3}{|c|}{$p$-value $=0.000$} & \multicolumn{3}{|c|}{$p$-value $=0.000$} & \multicolumn{3}{|c|}{$p$-value $=0.000$} \\
\hline
\end{tabular}

Notes: * significant at $10 \% ; * *$ significant at $5 \%$; *** significant at $1 \%$. Sample weights are used to take into account that individuals winning less than $€ 1,000$ are a $1 \%$ random draw from the population of small lottery winners. Standard errors are robust to heteroskedasticity and serial correlation.

\footnotetext{
${ }^{21}$ The joint significance tests of the six individual characteristics, if the ticket expenditures and the year fixed effects are not included in the equation for the lottery prizes, return the following $p$-values: 0.074 for $T=0 ; 0.001$ for $T=1 ; 0.027$ for $T=2 ; 0.458$ for $T=3$.
} 